\title{
OPTIMISATION OF LABORATORY PROTOCOLS FOR THE HISTOLOGICAL STUDY OF TRIALEURODES VAPORARIORUM WESTWOOD, 1856 (HEMIPTERA: ALEYRODIDAE) GONADS - Part 1
}

\author{
Daniel Kazimir Kurzeluk \\ Research-Development Institute for Plant Protection Bucharest, Romania \\ *correspondence address \\ Research and Development Institute for Plant Protection \\ Ion Ionescu de la Brad 8, CP 013813, Bucharest, Romania \\ e-mail: kurzelukdaniel@yahoo.com \\ http://www.doi.org/10.54574/RJPP.13.14
}

\begin{abstract}
Many techniques for the histological study of the invertebrate gonads topography are described. For arthropods, a major drawback is the presence of the exoskeleton, which is a hardly permeable structure to the aqueous reagents with mechanical resistance also. Therefore, use of specific reagents and techniques, adapted for the study of their internal structures is a must. Several methods have been tested in this study like aqueous topographical fixation solutions based on picric acid (Bouin), mercury (II) chloride (,Susa” Heidenhain) as well as alcoholic ones, picric acid (Duboscq-Brasil), mercury (II) chloride (Apathy) or acetic acid (Carnoy II) based. For the i) dehydration methods using absolute ethanol or 2-propanol, and ii) embedding ones the following methods were tested: paraffin with benzene, tert-butanol or pyridine as intermediary solvent (Gabe), paraffincelloidin double inclusion with diethyl ether: ethanol (1:1) as solvent (Pfuhl). After embedding and casting the paraffin blocks, these were cut at 5-10 $\mu$, the section ribbons were spread on distilled water and glued on slides with glycerol-albumine Mayer. For the double-embedded material, the sections were glued with Ruyter's solution, with or without application of collodion. Heidenhain's „Azan”, Mann-Dominici, Van Gieson and Gabe staining methods were used. For permanent slides, natural Canada balsam or artificial one "Caedax" were dissolved in xylene (mixture of isomers). Several procedures were tested for fixing solution, intermediary solvent, dehydrating, embedding and staining. The aim of this study was to optimise an efficient method in terms of results and reproducibility. Here, one of the successful methods is detailed (Heidenhain's „Susa” fixation, ethanol dehydrating, paraffin embedding and Heidenhain's „Azan” staining), to be followed by a series of optimized methods in future articles. The results obtained are reproducible, allowing the investigation methods of the structural modification of the white fly gonads induced by the chemical or biological control methods standardization.
\end{abstract}

Keywords: Trialeurodes vaporariorum, gonads, histology

\section{INTRODUCTION}

As in the Romanian specialised literature this topographical staining technique is rarely mentioned, also the histo-topographic studies on insect gonads being even fewer, this work may be useful for those who want to further investigate this subject with reproducible and adequate results.

More authors doubted the usefulness of the over-emphasised and widely used of the „Haemalum-Eosin” staining method (Langeron, 1942; Martoja \& Martoja, 1967; Gabe, 1968) considering it as outdated. Summary, not evidentiating any tinctorial affinity and overcome by many other methods with similar technical easiness but with far superior results. The use of this method until today, according to Gabe (1968) represents ,the triumph [...], as uncontestable as it is unworthy, is due to the indifference regarding the histological technique and to the routine spirit".

Thus, in a series of future works on this subject, some other fixation, inclusion and topographic staining methods tested by the author with outstanding results will be presented. The Heidenhain's „Azan” staining method as treated here according to Gabe (1968), quoted 
by Mureşan et al. (1974) and Untu (1976) is one of the most difficult techniques, but with brilliant results, being an adaptation of the classical protocol adapted by the author himself, in order to make it more accessible, because the original nuclear stain (Azocarmine B) became harder or even impossible to find, and because the other technical variants (using the FeulgenRossenbeck method, Nuclear fast red or Ziehl's carbolfuchsin doesn't show the same staining precision). Even so, both the original method and the quoted modifications are indicated at the end of this work, in order to make them accessible for those who wish to use them.

The aim of this paper is to present $s$ standardised method for the study of the microscopical anatomy of the whitefly (Trialeurodes vaporariorum) gonads. Precise timing schedules, preparation method as well as technical steps and tips are exposed, detailed and explained (where necessary).

\section{MATERIAL AND METHODS}

Trialeurodes vaporariorum adults were collected in 10 to $20 \mathrm{ml}$ screw-capped plastic vials. The fixation was performed in situ after $70 \%$ Ethanol (EtOH) vapour narcotisation of the insects. For the proper fixation of 20 individuals, $10 \mathrm{ml}$ of fixative solution were used. After one hour, the insects were transferred with the aid of a bacteriological loop in another vial containing $5 \mathrm{ml}$ of $70 \% \mathrm{EtOH}$, in which all the other steps of dehydrating and clarifying were performed, according to the protocol. The paraffin baths were kept in a thermostat at $60^{\circ} \mathrm{C}$, the insects being transferred with the aid of fine brass forceps with the tips kept in melted paraffin in the embedding oven and shortly heated in a small flame before using. Temperature control was assured by a mercury thermometer with the bulb immersed in a melted paraffin-containing tube placed inside the embedding oven. The casting of the block was performed with the aid of two Leuckart glass moulding bars (both the bars and the glass plate greased with a small drop of anhydrous glycerol). A quantity of molten paraffin was poured inside the bars and all the assembly was let aside on the bench until a thin layer of solidified paraffin formed at the bottom of the mould. The surface of the paraffin was shortly re-melted with a previously heated dissection pin. The specimens were transferred in the molten paraffin with the aid of a small brass forceps previously heated as the paraffin doesn't solidify on it. The orientation of the specimens in the melted paraffin was quickly performed with the aid of two previously heated dissection needles, under a Carl Zeiss SteREO Discovery.V8 stereomicroscope at a 50x magnification. After mounting on the microtome's disc, the paraffin block was trimmed, "faced" (block frontal face trimming) and sectioned (both at $5 \mu$, using different portions of the blade for "facing" and sectioning) with a planarconcave knife, the planar face being oriented towards the object, using a Reichert Minot paraffin rotary microtome. The paraffin removal and all the other section treatments (except staining) were performed in Borrel jars with ground cap (50 ml capacity), the staining was performed in Coplin jars (50 ml capacity) and the differentiation under microscopical control was performed in a glass Petri dish. Single-frosted end microscopical slides, engraved with a order number in a corner with the aid of a diamond glass engraving pen and $50 \mathrm{x} 22 \mathrm{~mm}$ cover glasses were used. The microscopical control was performed using a Carl Zeiss microscope with maximal magnification $1800 \mathrm{x}$.

Azocarmine B was used by the author instead of the original method which claims for the Azocarmine $G$ (which, even if the stain affinity for the nuclei is stronger and the colours are brighter is more expensive and more difficult to procure, also the necessity that the solution must be used at higher temperatures shortens its' life span and can lead to section loss, even if celloidin is used for coating). The solvents ( $\mathrm{Xyl}$ and diluted EtOH), the celloidin, the formalin-EtOH, the Lugol solutions and the aniline-alcohol were kept in Borrel jars with 
grounded cap, to avoid loses by evaporation. The stains and the differentiators were kept in Coplin jars (for the commodity of manipulation, chemical stability and saving). The absolute alcohol was kept in a dropping bottle and the Canada balsam dissolved in xylene in a groundcap bottle.

The de-staining of the slides in case of over- or un-satisfactory staining can be achieved with $1 \%$ ammonia water or with saturated aqueous lithium carbonate solution; both these solutions (especially the last one) decolorizes the stains used in less than 5 minutes.

The aniline-alcohol, the acetic alcohol, the phosphotungstic acid and the lithium carbonate solutions kept for years; replacement is needed if reddish tone gets darker. The undiluted Heidenhain's blue kept for 1 year, the diluted stain kept for 1 month maximum. The ammonia water must be freshly prepared.

The fixative solution as well as the fixative washing water, which contains mercury (II) salts and formalin (irritant, toxic, carcinogenic, mutagenic and hazardous for the environment) were collected in a tightly closed, Parafilm ${ }^{\mathrm{TM}}$ - sealed cap waste collecting plastic or glass recipient in order to be properly disposed. The used staining solutions were also collected in another waste collecting plastic or glass recipient. The used solvents were recovered, purified and reused.

Reagents and solvents used: Celloidin, Trichloroacetic acid (Carlo Erba), Diethyl ether, 96\% and absolute Ethanol, 37\% Formalin, Glacial acetic acid (Chemical Company), Azocarmine G (Gurr), Benzene, Calcium carbonate, Canada Balsam, Eosin B, elementary Iodine, Lithium carbonate, Orange G Phosphotungstic acid (Merck), Aniline blue (water soluble) (Riedel-DeHäen), 25\% Ammonium hydroxide solution, Aniline, anhydrous Glycerol, Mercury (II) chloride, Phenol, Potassium iodide, Sodium chloride, Sodium thiosulphate, o,m,p - Xylene (Reactivul), Thymol (Union Chimique Belge), Paraffin (M.P. 56-58 ${ }^{\circ} \mathrm{C}, 10 \%$ beeswax) (Reagent Plus).

The usual name, synonyms, Colour Index name and number as well are detailed in the Table 1, according to Gabe (1968) and Llewellyn (2019), the composition, name, functions, quantities and compounding procedures for the reagents used are detailed in the Table 2 (arranged according to the chronological use during the protocol), the staining results being described in the Table 3

Table 1. Stains used for the block- and topographical staining of Trialeurodes vaporariorum gonad sections

\begin{tabular}{l|l|l|l}
\hline \multicolumn{1}{c|}{ Name } & \multicolumn{1}{c|}{$\begin{array}{c}\text { Colour Index name and } \\
\text { number }\end{array}$} & \multicolumn{1}{c}{ Category } & \multicolumn{1}{c}{ Synonims } \\
\hline Azocarmine B & Acid Red 101 (50.090) & $\begin{array}{l}\text { Acid, } \\
\text { Quinon-imine }\end{array}$ & $\begin{array}{l}\text { Azocarmine GX, Rosazine, } \\
\text { Rosinduline GXF }\end{array}$ \\
\hline $\begin{array}{l}\text { Aniline blue, water soluble } \\
\text { (mixture of Methyl Blue and } \\
\text { Water Blue) }\end{array}$ & $\begin{array}{l}\text { Acid Blue 22 (42.755) } \\
\text { Acid Blue 93 (42.780) }\end{array}$ & $\begin{array}{l}\text { Acid, } \\
\text { Triarylmethane }\end{array}$ & $\begin{array}{l}\text { China blue, Cotton blue, Helvetia } \\
\text { blue, Methyl blue, Water blue, Aniline } \\
\text { blue }\end{array}$ \\
\hline Eosin B & $\begin{array}{l}\text { Acid red 91 } \\
(45.400)\end{array}$ & $\begin{array}{l}\text { Acid, Fluorone, } \\
\text { Xanthene }\end{array}$ & Eosine bluish, Imperial Red \\
\hline Acid Orange 10 (16.230) & Acid, Azo & Orange GG, Orange GPM \\
\hline
\end{tabular}

Table 2. Reagents used in the histological study of Trialeurodes vaporariorum gonad sections

\begin{tabular}{l|c|c|l|l}
\hline Reagent & Amount & Function & Compounding procedure \\
\hline Egg white & 1 part & MAYER'S ALBUMEN GLYCERINE \\
\hline Glycerol, & 1 part & Solvent & $\begin{array}{l}\text { Beat one egg white, until stiff. Let aside for 15 min. Decant the } \\
\text { liquid portion, without the chalaza, pour in a graduated cylinder, } \\
\text { mark the volume }\end{array}$ \\
\hline
\end{tabular}




\begin{tabular}{|c|c|c|c|c|}
\hline anhydrous & & & \multirow{2}{*}{\multicolumn{2}{|c|}{$\begin{array}{l}\text { graduated cylinder over the albumin, homogenise with a glass } \\
\text { rod avoiding foaming } \\
\text { Dissolve a crystal of the dimensions of half to a rice grain in the } \\
\text { minimum volume of } \mathrm{dH}_{2} \mathrm{O} \text { (usually } 0.25 \mathrm{~mL} \text { suffice), then mix } \\
\text { with the glycerol-albumen avoiding foaming. Use as such. }\end{array}$}} \\
\hline Thymol or phenol & 0.01 parts & $\begin{array}{l}\text { Bacterio- and fungi- } \\
\text { static agent }\end{array}$ & & \\
\hline \multicolumn{5}{|c|}{ HEIDENHAIN'S „SUSA” FIXATIVE } \\
\hline $\begin{array}{l}\text { Mercury (II) } \\
\text { chloride }\end{array}$ & $4.5 \mathrm{~g}$ & \multicolumn{2}{|c|}{ Additive coagulating fixative agent } & \multirow{6}{*}{$\begin{array}{l}\text { Weigh and dissolve the Mercury (II) chloride and } \\
\text { the sodium chloride in the water. Add the weighed } \\
\text { trichloroacetic acid, dissolve, then add the formalin } \\
\text { and the glacial AcOH and homogenise. Use as } \\
\text { such. }\end{array}$} \\
\hline Sodium chloride & $500 \mathrm{mg}$ & \multicolumn{2}{|c|}{$\begin{array}{l}\text { Indifferent salt, increases the } \\
\text { solubility of the mercury (II) } \\
\text { chloride in water }\end{array}$} & \\
\hline $\begin{array}{l}\text { Trichloroacetic } \\
\text { acid }\end{array}$ & $2 \mathrm{~g}$ & \multicolumn{2}{|c|}{$\begin{array}{c}\text { Non-additive coagulating fixative } \\
\text { agent }\end{array}$} & \\
\hline $\begin{array}{l}\text { Distilled water } \\
\left(\mathrm{dH}_{2} \mathrm{O}\right)\end{array}$ & $80 \mathrm{ml}$ & \multicolumn{2}{|c|}{ Solvent } & \\
\hline $\begin{array}{l}\text { Neutralised 37\% } \\
\text { formalin }\end{array}$ & $20 \mathrm{ml}$ & \multicolumn{2}{|c|}{$\begin{array}{c}\text { Additive, non-coagulating fixative } \\
\text { agent }\end{array}$} & \\
\hline $\begin{array}{l}\text { Glacial acetic } \\
\text { acid (glac. } \\
\text { AcOH) }\end{array}$ & $4 \mathrm{ml}$ & \multicolumn{2}{|c|}{$\begin{array}{l}\text { Non-additive, non-coagulating } \\
\text { fixative agent }\end{array}$} & \\
\hline \multicolumn{5}{|c|}{ LUGOL'S IODINE SOLUTION } \\
\hline $\begin{array}{l}\text { Elementary } \\
\text { iodine }\end{array}$ & $1 \mathrm{~g}$ & \multicolumn{2}{|c|}{$\begin{array}{c}\text { Mercury solubiliser by complexion } \\
\text { agent }\end{array}$} & \multirow{3}{*}{$\begin{array}{l}\text { Weigh the potassium iodide, dissolve it in the } \\
\text { water, then weigh and add the iodine. Mix well. } \\
\text { Use as such. }\end{array}$} \\
\hline Potassium iodide & $2 \mathrm{~g}$ & Iodine solubi & & \\
\hline $\mathrm{dH}_{2} \mathrm{O}$ & $100 \mathrm{ml}$ & Solvent & & \\
\hline \multicolumn{5}{|c|}{ SODIUM THIOSULPHATE SOLUTION } \\
\hline $\begin{array}{l}\text { Sodium } \\
\text { thiosulphate } \\
\text { pentahydrate }\end{array}$ & $5 \mathrm{~g}$ & \multirow{2}{*}{\multicolumn{2}{|c|}{ Decolourising (reducing) agent }} & $\begin{array}{l}\text { Weigh the sodium thiosulphate and dissolve it in } \\
\text { the water. Use as such. }\end{array}$ \\
\hline $\mathrm{dH}_{2} \mathrm{O}$ & $100 \mathrm{ml}$ & & & \\
\hline \multicolumn{5}{|c|}{ CELLOIDIN SOLUTION } \\
\hline $\begin{array}{l}5 \% \text { Celloidin } \\
\text { solution }\end{array}$ & $1 \mathrm{ml}$ & \multicolumn{2}{|c|}{ Protective film producing agent } & \multirow{3}{*}{$\begin{array}{l}\text { Mix the EtOH and the Et } 2 \mathrm{O} \text {, then add the celloidin } \\
\text { solution and homogenise. Use as such. }\end{array}$} \\
\hline Absolute EtOH & $24.5 \mathrm{ml}$ & Solvent & & \\
\hline $\begin{array}{l}\text { Anhydrous } \\
\text { diethyl ether } \\
\left(\mathrm{Et}_{2} \mathrm{O}\right)\end{array}$ & $24.5 \mathrm{ml}$ & Solvent & & \\
\hline \multicolumn{5}{|c|}{ EtOH-FORMALIN MIXTURE } \\
\hline EtOH 96\% & $90 \mathrm{ml}$ & \multirow{2}{*}{\multicolumn{2}{|c|}{$\begin{array}{c}\text { Celloidin and albumen coagulant } \\
\text { Albumen coagulant }\end{array}$}} & \multirow{2}{*}{ Mix the two reagents. Use as such. } \\
\hline $37 \%$ Formalin & $10 \mathrm{ml}$ & & & \\
\hline \multicolumn{5}{|c|}{ EOSIN B SOLUTION } \\
\hline Eosin B & $0.001 \mathrm{~g}$ & \multicolumn{2}{|l|}{ Stain } & \multirow{2}{*}{ Dissolve the stain in $70 \% \mathrm{EtOH}$. Use as such } \\
\hline abs. EtOH & $1 \mathrm{ml}$ & Solvent & & \\
\hline \multicolumn{5}{|c|}{ AZOCARMINE B SOLUTION } \\
\hline Azocarmine B & $500 \mathrm{mg}$ & \multicolumn{2}{|c|}{ Dye } & \multirow{3}{*}{$\begin{array}{l}\text { Add the ingredients in the listed order. Dissolve } \\
\text { with stirring. If necessary, filter before use. Use as } \\
\text { such. }\end{array}$} \\
\hline $\mathrm{dH}_{2} \mathrm{O}$ & $100 \mathrm{ml}$ & Solvent & & \\
\hline glac. $\mathrm{AcOH}$ & $2 \mathrm{ml}$ & Acidifier & & \\
\hline \multicolumn{5}{|c|}{ ANILINE ALCOHOL } \\
\hline EtOH $96 \%$ & $100 \mathrm{ml}$ & Solvent & & \\
\hline Aniline & $0.1 \mathrm{ml}$ & Differentia & & Mix the aniline with the alcohol. Use as such. \\
\hline & & $\mathrm{ACE}$ & $\mathrm{C}$ ALCOHC & \\
\hline AcOH glac. & $1 \mathrm{ml}$ & Differentia & & Miv the acetic acid with the alcohol Use as cuch \\
\hline EtOH 96\% & $100 \mathrm{ml}$ & Solvent & & Mix the acetic acid with the alcohol. Use as such. \\
\hline & & PHOSPHOTUN & STIC ACID & OLUTION \\
\hline $\begin{array}{l}\text { Phosphotungstic } \\
\text { acid }\end{array}$ & $5 \mathrm{~g}$ & Mordant and diffe & tiator & Dissolve the phosphotungstic acid in the water. \\
\hline $\mathrm{dH}_{2} \mathrm{O}$ & $100 \mathrm{ml}$ & Solvent & & \\
\hline
\end{tabular}




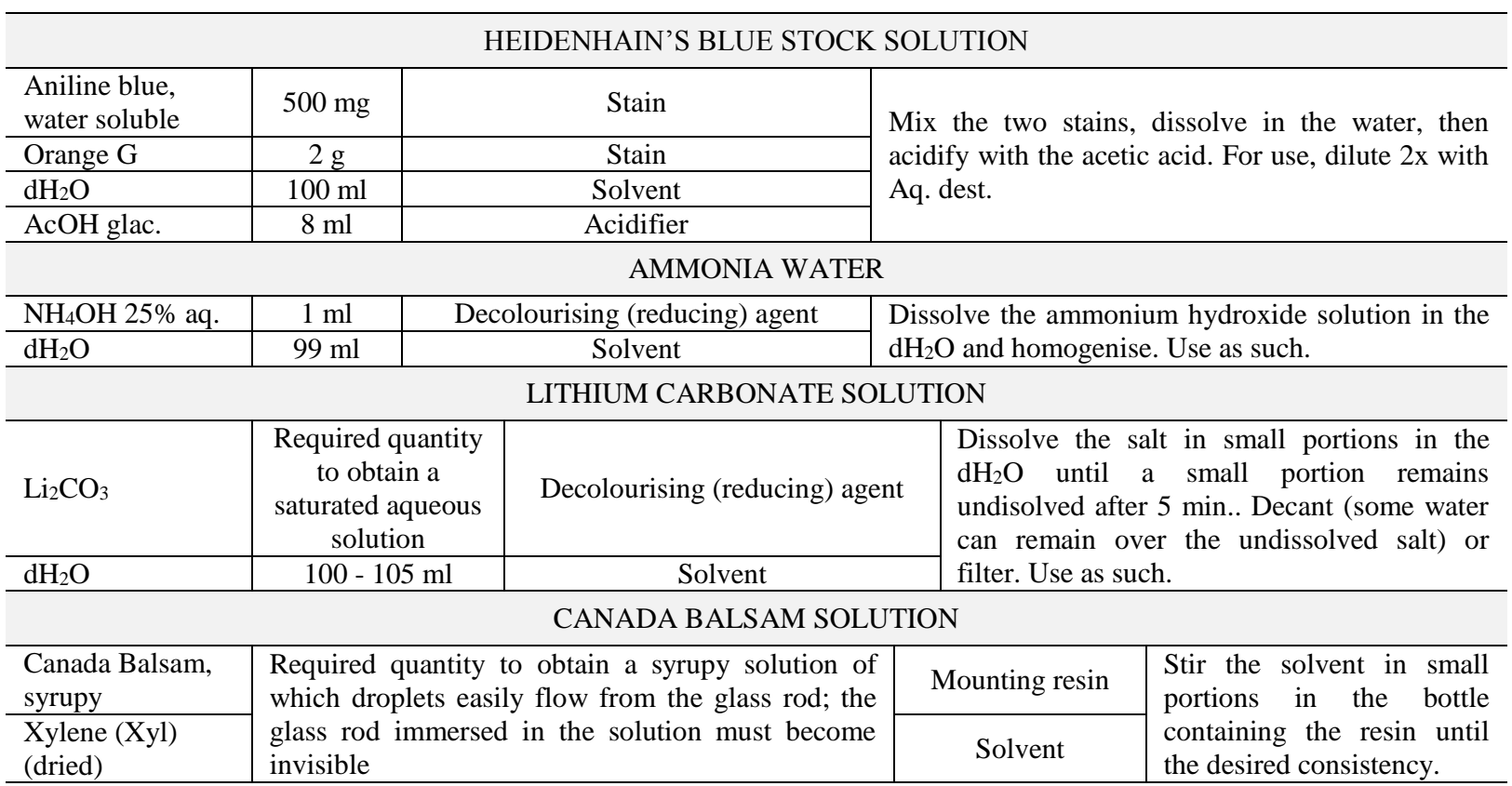

Fixation, dehydrating, clarifying, embedding and sectioning This protocol is partially taken and compiled from Blackburn et al. (2002), Humason (1962), Langeron (1942), Gabe (1968), Martoja \& Martoja (1967) and Mureşan et al. (1974) but was modified, adapted and further developed by the author and includes the following steps:

1. Adult collection and immobilisation with $70-90 \%$ EtOH vapours

2. Killing by immersion in Heidenhain's „Susa” fixative (10 mL for up to 20 individuals), shaking a couple of times (care must be taken as the individuals should remain immersed), $1 \mathrm{~h}$

3. Dehydrating: EtOH 70\%, 1 x 30 min.; EtOH 96\%, 1 x 30 min.; EtOH abs. 3 x 30 min.

4. Specimen in toto (block) staining: Eosin B 0.1\% in abs. EtOH: $30 \mathrm{sec}$.

5. Short washing in abs. EtOH: 1-2 x $5-10 \mathrm{sec}$. (the specimens must retain the pink colour)

6. Clarifying: Benzene (Bz) 3 x 30 min.

7. Embedding: Paraffin (M.P. $\left.56-58^{\circ} \mathrm{C}\right) 1 \times 24 \mathrm{~h}, 2 \times 1 \mathrm{~h}$ (sepparate baths)

8. Block casting

9. Cooling in tap water: $15 \mathrm{~min}$

10. De-mold and dry thoroughly the block by blotting it with filter paper

11. Block side faces trimming (two of them must be parallel)

12. Mounting paraffin block on the microtome's object disc

13. Leave to rest for $24 \mathrm{~h}$, room temperature

14. Mount the object disc on the microtome, "face" the block $(5 \mu)$, verify if the sections ribbon forms regularly

15. Sectioning: $5 \mu$

16. Cut the section ribbons in portions of which length (after stretching) can be coverslipped with a margin of $+/-1 \mathrm{~cm}$ around

17. Place the sections on cleaned slides covered with a thin film of Mayer's glycerol-albumen mixture, dried and heated for 2-3 x 1-2 sec.

18. Add several drops of $\mathrm{dH}_{2} \mathrm{O}$ and float the sections or ribbons on the water. Warm short and gently ("step onto" a small flame) until the paraffin becomes smooth and without wrinkles for 0.5 - 1 sec., $2-3 \mathrm{x}$ (the paraffin must not melt). If necessary, ribbons may be straightened with a needle at each end, pulling gently. Carefully drain the water. Let sections dry in a dust-free space for one day. 
19. Paraffin removing: Warm short (same technique) for 1-2 seconds $2-3 x$ (the paraffin can melt), Tol / Xyl (10-15 min.) 3x

20. Replace Tol / Xyl by abs. EtOH: short rinsing (2-3 seconds) with abs. EtOH (2-3x)

21. Celloidin-coating: Celloidin 5\% $30 \mathrm{sec}$., draining by slowly removal of the slide in vertical position from the celloidin solution for draining

22. Final solidification of the celloidin film by immersion in EtOH 96\%: $37 \%$ formalin $(1: 1)$ for $30 \mathrm{sec}$.

23. $96 \%$ EtOH (1-2 min.), $70 \%$ EtOH (1-2 min.)

24. Hydrating: $\mathrm{dH}_{2} \mathrm{O}$ for $5 \mathrm{~min}$.

25. Staining and mounting (coverslipping): see next section - Heidenhain's „Azan”

26. Dry for $72 \mathrm{~h}$ at room temperature or for $24-48 \mathrm{~h}$ at $45-50^{\circ} \mathrm{C}$ (horizontally)

27. Remove Canada Balsam excess around the coverslip (if any) by means of a soft tissue imbibed in Xyl.

28. Label and store in collection.

Heidenhain's „Azan” (1916) This protocol is taken from Gabe (1968), but was adapted by the author and includes the following steps:

1. Deparaffinised sections, celloidin-coated if necessary, hydrated

2. Staining with the Azocarmine B solution: $1 \mathrm{~h}$, room temperature

3. $\mathrm{dH}_{2} \mathrm{O}$ rinsing: $2-3 \mathrm{x}$

4. Differentiation under microscopical control (take the slide out of the solution, put it in a

Petri dish on the microscope plate, cover with aniline-alcohol): $2-3$ minutes (rarely less)

5. Acetic alcohol: $30 \mathrm{sec}-1 \mathrm{~min}$.

6. $\mathrm{dH}_{2} \mathrm{O}$ rinsing: $2-3 \mathrm{x}$

7. Phosphotungstic acid solution: $30-60 \mathrm{~min}$.

8. $\mathrm{dH}_{2} \mathrm{O}$ rinsing: $2-3 \mathrm{x}$

9. Heidenhain's blue diluted solution: 30-60 min.

10. If necessary, $\mathrm{dH}_{2} \mathrm{O}$ rinsing, then with $\mathrm{EtOH} 96 \%$, or direct dehydrating with absolute $\mathrm{EtOH}$

11. Clarification: Xyl: 3 x 15-30 sec.

12. Canada Balsam mounting.

\section{RESULTS AND DISCUSSIONS}

The results of the staining protocol applied on $T$. vaporariorum gonad sections are detailed in the table 3 .

Table 3. Staining results using the Heidenhain's "Azan" modified method applied on Trialeurodes vaporariorum gonad sections

\begin{tabular}{l|l}
\hline \multicolumn{1}{c|}{ Cell components and tissues } & \multicolumn{1}{c}{ Colour } \\
\hline Nuclei & red to red with a slight nuance of violet, precisely delineated \\
\hline Cytoplasms & mostly golden yellow \\
\hline Collagen & deep blue \\
\hline Secretion products & intense red - pink - yellow - light to deep blue- violet \\
\hline Acid mucopolysaccharid-rich structures & light blue \\
\hline Striated muscular fibers & (depends on differentiation): red - orange - yellow \\
\hline Elastic fibers & clear \\
\hline Fibrogliae and nervous tissue & sometimes pink \\
\hline
\end{tabular}




\section{Technical comments}

Mayer's albumen-glycerol slide coating: on clear, heat slides over a small flame (for 1-2 sec.), let cold, apply a small amount of Mayer's albumen-glycerol solution (one droplet with a diameter smaller than $1 \mathrm{~mm}$ suffice), distribute evenly with the index in a very thin film. Let dry, heat shortly over a small flame and keep on a wooden raster (Vigier's raster) albumen-side down until use.Celloidin-coating is achieved by immersing the slide in a $0.1 \%$ celloidin in Et2O: EtOH (both anhydrous). The slide is kept in the solution for 5-10 seconds, then is removed by a very slow vertical motion so the celloidin solution can evaporate progressively in order to form a thin film. The Azocarmine B staining is best applied after sections hydration, in case of fixation by most fixing solutions; if the object have been fixed for a long period in an acid fixative, or if chitin softening was applied before staining, the slides must undergo a aniline alcohol bath (same recipe as the differentiator solution) for no more than 30 min.. Same for the Azan technique is applied after staining methods in acid medium (Romeis's "Kresazan"). After the aniline-alcohol bath, the slides will be shortly rinsed with $\mathrm{dH}_{2} \mathrm{O}$.

The differentiation is performed under microscopic control, the slide being removed from the aniline-alcohol and examined at feeble magnification (5x Objective, 5 or $10 \mathrm{x}$ Ocular); at this moment, a short examination of the preparation is recommended. The colour should be a uniform, intense red, with the exception of some structures which never stain with Azocarmine B. In some cases, the differentiation by simple (without aniline) EtOH $96 \%$ is possible.

The decolorizing time for the preparation requires 2 to 3 minutes, sometimes less. The more diluted the alcohol (down to $70 \%$, tested by successive diluted solutions trials), the easier the differentiation. The strength of the nuclear stain and of some secretion products reveals the limits of the differentiation (you can't over differentiate; so, a proper differentiation is performed, when the microscopic control shows the almost perfect staining of the nuclei).

The phosphotungstic acid extracts almost completely the Azokarmine B retained by the collagen fibers, of which complete distaining can be obtained even in the absence of the aniline-alcohol differentiation (use simple 96\% EtOH). When de-staining with the phosphotungstic acid, scrupulous care must be exerted by following the differentiation progress, because, even if the stain strength, in case of longer differentiations, the muscular fibers stain, or even the cytoplasmic one can be washed away.

Staining progress markers (a) too short differentiation = general colour red; (b) too prolonged differentiation $=$ general colour yellow and blue; $(\mathbf{c})$ excessively prolonged differentiation $=$ the aniline blue overstains the nuclei, giving a "horrible muddish teint" (cf. Gabe, 1968). The differentiation can be stopped by immersing the slide in acetified alcohol. The slides can be kept in this solution at least $30 \mathrm{sec}$, but they can remain for hours without any damage. The aniline-alcohol treatment can be an excellent stop point when the time doesn't allow achieving the staining in one working séance. The phosphotungstic acid treatment asks usually for 30 (sometimes up to $60 \mathrm{~min}$., but in some cases, even $20 \mathrm{~min}$. suffice), but can be adjusted according to the way the Azocarmine B differentiation was conducted and accordingly to the demanded final result. (d) If the aniline-alcohol differentiation was prolonged, the phosphotungstic acid differentiation will be shortened accordingly. Only if after the aniline-alcohol differentiation a strong red cytoplasm stain continues, the phosphotungstic acid treatment will be prolonged up to $3 \mathrm{~h}$ even more. The final point of the phosphotungstic acid differentiation can be spotted when the collagen fibres are completely de-stained, at this moment (after a short $\mathrm{dH}_{2} \mathrm{O}$ rinsing in order to remove the phosphotungstic acid) the slides can be stained with Heidenhain's blue solution. - The staining period with the 
Heidenhain's blue solution varies according to how the differentiation was conducted and also to the duration of the phosphotungstic solution differentiation.

(d) A prolonged differentiation with aniline-alcohol and the shortening of the phosphotungstic acid differentiation asks for a shorter Heidenhain's blue staining and vice versa.

(f) If an intense collagen staining is desired, if the aniline-alcohol differentiation was prolonged and the other technical times shortened, dehydration can be achieved directly with absolute EtOH, which doesn't dissolve the Aniline blue-stained collagen fibres.

(g) The 96\% EtOH washing increases the preparation transparency, but diminishes the intensity of the blue stain; washing with $\mathrm{dH}_{2} \mathrm{O}$ is not recommended until a too strong staining of the nuclei with Aniline blue is obtained.

In any case, a Heidenhain's blue staining over one hour is not recommended - the fresh solutions gave blue tones, the older solutions yellowish tones.

\section{Technical variants using other nuclear stains}

a) Azocarmine $\mathbf{G}$ - This is the original nuclear staining method, as described by Gabe (1968). The reagents used and the working steps are the following:

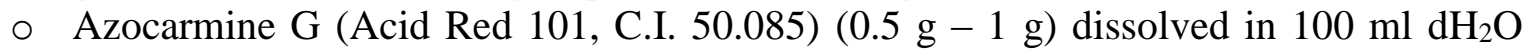
acidified with 1-2 ml glacial $\mathrm{AcOH}$. Kept well at room temperature, at $60^{\circ} \mathrm{C}$ can be used only 12 days.

○ Aniline alcohol (70\% EtOH $100 \mathrm{ml}$, aniline $1 \mathrm{ml})$

- Other reagents (phosphotungstic acid, Heidenhain's blue, acetic alcohol) are the same as in the Azocarmine B method

1. The Azocarmine G solution must be heated at $60^{\circ} \mathrm{C}$. The sections are stained for $1 \mathrm{~h}$ at this temeperature, then removed from the staining solution and immediately rinsed with $\mathrm{dH}_{2} \mathrm{O}$.

2. The differentiation is to be conducted as in the Azocarmine B method, but use $1 \%$ aniline in $70 \% \mathrm{EtOH}$.

3. Acetic alcohol treatment: $30-60 \mathrm{sec}$. Short rinsing with $\mathrm{dH}_{2} \mathrm{O}$.

4. Phosphotungstic acid solution: $30-60 \mathrm{~min}$. Short rinsing with $\mathrm{dH}_{2} \mathrm{O}$.

5. Heidenhain's blue diluted solution: 30-60 min. Short rinsing with $\mathrm{dH}_{2} \mathrm{O}$.

6. $96 \% \mathrm{EtOH}$, then absolute $\mathrm{EtOH}$, clarify, mount in Canada Balsam or synthetic resin.

The sections must not be leaved in the staining solution, because stain crystals can form on sections when the solution returns to room temperature.

b) Nuclear Fast Red - A nuclear staining method which doesn't need differentiation, because of the stain precision. The reagents used and the technical steps are as follows:

- Nuclear Fast Red (Calcium Red, Helio Fast Rudin BBL, Kernechtrot, Rouge nucleaire solide, C.I. 60.760) (0.1 g) and Aluminium sulphate $(5 \mathrm{~g})$ are dissolved with heating in

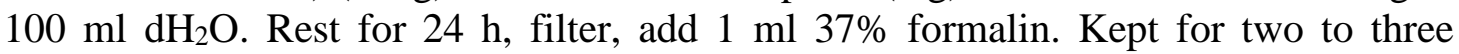
monts. The other solutions are the same as in the Azocarmine G method.

1. Stain for 2 - 4 min. Short rinsing with $\mathrm{dH}_{2} \mathrm{O}$.

2. Treat with the phosphotungstic acid solution for $5 \mathrm{~min}$. at least. Short rinsing with $\mathrm{dH}_{2} \mathrm{O}$.

3. Stain with Heidenhain's blue for 5 - 10 min. at least. Short rinsing with $\mathrm{dH}_{2} \mathrm{O}$.

4. Dehydrate with absolute EtOH, clarify, mount in Canada Balsam or synthetic resin.

c) Ziehl's carbolfuchsin - A classical staining method used in bacteriology, which also can serve as a good nuclear stain with good precision, is to be prepared and used as follows:

- Diamant fuchsin (Basic fuchsin, Magenta, Pararosaniline, Fuchsine) (1g) homogenized in mortar with phenol $(5 \mathrm{~g})$, add $10 \mathrm{ml} \mathrm{EtOH} \mathrm{96 \% ,} \mathrm{add} 90 \mathrm{ml} \mathrm{dH}_{2} \mathrm{O}$ in 
small portions with stirring, filter. Kept for months. Prior to use, dilute 1 volume of solution with 9 volumes of $\mathrm{dH}_{2} \mathrm{O}$.

1. Stain for $10 \mathrm{~min}$. at room temperature. Short rinsing with $\mathrm{dH}_{2} \mathrm{O}$.

2. $0.3-0.5 \% \mathrm{AcOH}$ until the excess stain is removed. The rest of the protocol is the same as for the Nuclear Fast Red method.

d) Feulgen-Rossenbeck - The Schiff aldehyde identification reaction as used by chemists and modified for the chromosome morphology study by Feulgen and Rossenbeck have been adapted for nuclei staining by Huber (1946), quoted by Gabe (1969). The reagents and the working method are as follows:

○ Schiff's reagent (acc. to Graumann): Diamant fuchsin $(0.5 \mathrm{~g})$ dissolved in $15 \mathrm{ml} \mathrm{N}$ $\mathrm{HCl}\left(80 \mathrm{ml} \mathrm{37 \%} \mathrm{HCl}-\mathrm{d}=1.19 \mathrm{~g} / \mathrm{cm}^{3}, \mathrm{dH}_{2} \mathrm{O} 920 \mathrm{~mL}\right)$. Dissolve $0.5 \mathrm{~g}$ anhydrous

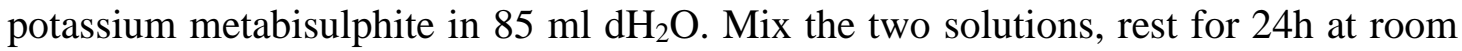
temperature. If necessary, decolorize by adding $0.3 \mathrm{~g}$ activated charcoal, mix thoroughly for $15-30 \mathrm{sec}$., let decant and filter. The solution must be light yellow.

- Sulfurous water: Sodium or potassium metabisulphite $1 \%$ solution acidified with III-V drops $\mathrm{N} \mathrm{HCl}$.

1. Deparafined and celloidin - coated sections. Acid hydrolysis: $\mathrm{N} \mathrm{HCl}$ solution, 75 min. room temperature $/ 105 \mathrm{~min}$. at $55^{\circ} \mathrm{C}$. Wash in tap water.

2. Schiff reagent: $1 \mathrm{~h}$, room temperature, wash vigorously in sulfurous water, room temperature. The rest of the protocol is the same as the original one.

\section{CONCLUSIONS}

The precise timing for each of the technical steps is provided, from individual collecting to the drying of the final preparation.

The solutions' composition and preparation methods are detailed, including the scope of each component.

The accepted and regulated international names and codes, synonyms and structural class of the used dyes are clearly indicated.

The original method have been adapted in order to use the Azocarmine B instead of the Azocarmine $\mathrm{G}$ stain, which it became difficult to procure, and, despite its' staining precision its' use is more difficult than the Azocarmine B.

The staining method is fully detailed, containing also "staining progress markers", which act both as a method progress verification and as indicators of the following technical steps duration and application.

The variants using other nuclear stains are indicated, for each of them a short technical note concerning the preparation and the use being given.

The results obtained are reproducible, allowing the investigation methods of the structural modification of the white fly gonads induced by the chemical or biological control methods standardization.

The protocol as it is, can be successfully applied, the technical notes and comments can be really helpful to all who would like to apply this histo-topographical method, from technicians to researchers.

\section{Acknowledgements}

This work was realized in the frame of the project "Innovative protection technology for protected spaces crops by superior valorification of the autochthonous biological control agents" no. 4686/2015 
financed by the Ministry of Agriculture and Rural Development through the Academy of Agricultural and Forestry Sciences.

\section{REFERENCES}

BLACKBURN, B.M., GELMAN, D.B., HU, J.S. (2002). Co-Development of Encarsia formosa (Hymenoptera: Aphelinidae) and the Greenhouse Whitefly, Trialeurodes vaporariorum (Homoptera: Aleyrodidae): A Histological Examination. Archives of Insect Biochemistry and Physiology, 51, $13-$ 26.

GABE, M. (1968). Techniques histologiques, Masson et Cie., Éditeurs, Paris, 1113.

HUMASON, G. (1962). Animal tissue techniques. W.H. Freeman and Company, San Francisco and London, 468.

LANGERON, M. (1942). Précis de microscopie. Masson et Cie., Paris, 1340.

LLEWELLYN, B.D., StainsFile Internet site, http://stainsfile.info/ [updated 2019 January; cited 2021 January 31].

MARTOJA, R., MARTOJA-PIERSON, M. (1967). Initiation aux techniques de l'histologie animale. Masson et Cie., Paris, 345.

MUREŞAN, E., GABOREANU, M., BOGDAN, A.T., BABA, A.I. (1974). Tehnici de histologie normală şi patologică. Ed. Ceres, Bucureşti, 476.

UNTU, C. (1976). Tehnica întocmirii preparatelor de histologie animală, 283-328, in: ANGHEL, I., UNTU, C., TUDOR, C., MEŞTER, L., NĂSTĂSESCU, M., TOMA, N., GREGORIAN, L., NIŢESCU, E. (1976). Practicum de biologie. Tipografia Universităţii din Bucureşti, 354. 